\title{
La promesa de lo bello: consideraciones acerca de la estética filosófica hacia finales del siglo XVIII
}

\author{
The promise of beauty: considerations about \\ philosophical aesthetics in the late eighteenth \\ century
}

\author{
María Verónica GALFIONE \\ Universidad Nacional de Córdoba - CONICET (Argentina)
}

Recibido: 21-05-2013

Aceptado: 21-11-2013

\section{Resumen}

El presente trabajo analiza algunas de las estrategias por medio de las cuales la reflexión estética de finales del siglo XVIII intentó dar respuesta al problema de la legitimación de la representación artística. Entre ellas es considerada con particular atención la redefinición del concepto de belleza que propone Immanuel Kant en la Crítica de la facultad de juzgar. A partir de la revisión de la postura kantiana, se pone en evidencia la conexión existente entre la crisis de fundamentación de la belleza artística y la debacle de la historia natural clásica, por una parte. Por la otra, se procura dar cuenta de la modificación del estatuto y de las funciones de la esfera estética que introduce el vuelco kantiano hacia el ámbito de la subjetividad.

Palabras clave: belleza, naturaleza, representación artística, teleología.

\begin{abstract}
This paper analyzes the strategies that the aesthetic reflection in the late eighteenth century set out to address the problem of artistic representation legitimacy. Among them, we closely consider the redefinition of "beauty" proposed by Kant in the Kritik der Urteilskraft. By reviewing Kant's position, we intend to show, on the one hand, the connection between the justification of artistic beauty crisis and the debacle of classical natural history. On the other hand, we seek to highlight the aesthetic sphere's change of status and function introduced by the Kantian turn towards subjectivity.
\end{abstract}

Keywords: Beauty, Nature, Artistic representation, Teleology. 


\section{Introducción}

El presente trabajo se inscribe en una investigación de mayor alcance que indaga los vínculos existentes entre el problema de la legitimación de la representación artística, hacia finales del siglo XVIII, y la crisis de las categorías histórico-naturales clásicas. Con esto último hacemos referencia al proceso de temporalización de los fenómenos naturales que puso en cuestión aquella articulación entre el abordaje mecanicista y la explicación teleológica que habían hecho posible las teorías biológicas del siglo XVII ${ }^{1}$. Estas corrientes, cuyas primeras formulaciones remitían a Marcello Malpighia o Jan Jakob Swammerdam, y cuya fundamentación filosófica puede encontrarse en Gottfried Wilhelm Leibniz, sostenían que los diferentes momentos del desarrollo de un ser vivo se hallaban prefigurados en el germen desde el momento de la fecundación. ${ }^{2}$ De esta manera, las concepciones preformistas podían dar cuenta del carácter teleológico de las configuraciones orgánicas sin renunciar a la posibilidad de explicar el desarrollo de las mismas en términos estrictamente mecánico-causales. En este sentido, la teoría de los gérmenes prefigurados permitía establecer un puente entre la ciencia y la religión. Pues, la configuración de los seres orgánicos era remitida a la voluntad divina, pero el alcance de esta última quedaba restringido al momento inicial de la creación. ${ }^{3}$ Sin embargo, este procedimiento introducía un drástico recorte de las facultades

1 Cf. Wolf Lepenies. Das Ende der Naturgeschichte. Frankfurt: Suhrkamp, 1978, pp. 16-8; Miche Foucault. Las palabras y las cosas. Trad. Elsa Cecilia Frost. Barcelona: Planeta, 1984, p. 137.

2 El preformismo biológico negaba la posibilidad de que en el lapso temporal que mediaba entre la fecundación y la formación definitiva del organismo se produjesen transformaciones morfológicas. El desarrollo de los seres naturales consistía así en un proceso mecánico a lo largo del cual maduraban una serie de disposiciones que se hallaban depositadas antes de la fecundación o bien en el óvulo o bien en el espermatozoide. En cualquier caso, el desarrollo evolutivo no suponía la creación de partes nuevas sino el desenvolvimiento de aquellos órganos que se hallaban replegados desde un comienzo. En este sentido, el preformismo le atribuía al concepto de "evolución" un significado contrario al que esta palabra adquiriría a partir del siglo XIX. Cf. Elías Palti. Aporías. Tiempo, modernidad, sujeto, historia, nación. Buenos Aires: Alianza, 2001, pp. 35-6; Gottfried W. Leibniz. Los principios de la naturaleza y de la gracia. Trad. García Morente. México: Porrúa, 1977, p. 64. En el plano filogenético el preformismo tenía como correlato la teoría del encapsulamiento múltiple. Pues si cada ser vivo estaba prefigurado en las semillas depositadas por su progenitor o su progenitora, en su propio germen debían hallarse replegados también, en un tamaño aún más reducido, los organismos completos de su entera descendencia. En última instancia, debía existir un óvulo o un espermatozoide primero en el cual se encontrasen encapsuladas, unas dentro de otras, cada una de las generaciones posteriores. Sobre este tema, se pueden consultar los trabajos de: Igor Polianski. "Natursystem, Systemästhetik und das Überleben der Physikotheologie. Eine Jenaer Botanikgeschichte um 1800“. Reinhard Wegner (Ed.) Kunst-Die andere Natur. Göttingen: Vandenhoeck y Ruprecht, 2004, pp. 125-134; Gian France Frigo. „Die stete und feste Gang der Natur zur Organisation“. Olaf Breidbach y Paul Ziche (Eds.) Naturwissenschaften um 1800. Weimar: Hermann Böhlaus Nachfolger, 2001, pp. 27-46; Johannes Bierbrodt. Naturwissenschaft und Ästhetik, 1750-1810. Würzburg: Königshausen und Neumann, 2000, p. 187; Stefan Metzger. Die Konjektur des Organismus Wahrscheinlichkeitsdenken und Performanz im späten 18. Jahrhundert. München: Wilhelm Fink, 2002, pp. 29-40.

3 En este sentido señalaba Leibniz: "si Dios hace milagros, esto sucede, según creo, no porque la naturaleza se lo exija, sino su piedad: juzgar esto de otra forma supondría tener una representación realmente baja de la fuerza y la sabiduría de Dios" Gottfried W. Leibniz. Der Briefwechsel mit G.W. 
sobrenaturales. Por este motivo, Pierre-Simon Laplace llegaría a caracterizar a Dios como una hipótesis de carácter innecesario ${ }^{4}$. Ya que, aun cuando la voluntad divina dispusiese las formas originarias, el desenvolvimiento de las mismas solo podía ser explicado a partir de la acción mecánica de los diversos factores naturales.

Este acuerdo entre ciencia y religión resultaba dependiente de una particular concepción de la temporalidad que excluía por principio toda posible asimetría entre el pasado y el futuro. Esta concepción "reversible" de la temporalidad permitía garantizar la conservación de las intenciones divinas a lo largo del desarrollo evolutivo y aseguraba, de esta forma, la coincidencia entre las disposiciones finales y las cadenas mecánico-causales. No obstante, las nuevas investigaciones científicas del siglo XVIII tendieron a poner en duda este presupuesto y a socavar, en tal sentido, la confianza preformista en la finalidad de las formas orgánicas naturales. La posibilidad de incorporar el principio de la temporalidad en los análisis naturales fue considerada por primera vez en el ámbito de las ciencias taxonómicas clásicas. Esto último puede apreciarse de manera paradigmática en el caso de Georges-Louis Leclerc Buffon, quien sostuvo la existencia de una "degeneración" de las formas vivas e incorporó la hipótesis de una "historia de la tierra". Sin embargo, tampoco Buffon llegó a concebir la posibilidad de que el tiempo desempeñara un papel determinante en la constitución de los seres naturales. Pues, desde su punto de vista, las transformaciones orgánicas que se registraban a lo largo de la historia respondían al efecto limitante que ejercían los diferentes factores climáticos sobre el poder de estructuración de un principio de carácter atemporal: la moule intérieur 5 .

Según hemos mostrado en otro lugar6, la resistencia del naturalista francés a admitir una concepción irreversible de la temporalidad se desprendía de las consecuencias epistémicas de la misma. Puesto que, si se asumía la existencia de transformaciones orgánicas no-reversibles se volvía necesario postular la existencia de una guía de carácter providencial a los fines de explicar el surgimiento de las formas naturales organizadas. Sin embargo, la idea de una temporalidad de naturaleza irreversible recibiría un notable empuje durante las últimas décadas del siglo XVIII. Entre los elementos que es necesario mencionar a la hora de dar cuenta del progresivo abandono de la noción clásica de la temporalidad merecen una atención especial sucesos tan dispares como el descubrimiento de nuevos yacimientos fósiles, ${ }^{7}$ el terremoto de Lisboa ${ }^{8}$ o la publicación de las investigaciones embriológicas de Caspar

Leibniz von 1715/1716. Hamburg: Felix Meiner, 1990, pp. 10-1. Aquí y en todos los casos en los cuales no se consigne lo contrario, la traducción ha sido realizada por la autora de este artículo.

4 Cf. Elías Palti. Op. cit. p. 33.

${ }^{5}$ Cf. Georges-Louis Leclerc Buffon. Histoire Naturelle, Générale et Particulière, avec la description du Cabinet du Roy. Tome Sixième. Paris: de l'Imprimerie Royale, 1756, pp. 299-301 (entre otros pasajes).

${ }^{6}$ Cf. María Verónica Galfione. "Historia Natural y temporalización: Algunas consideraciones sobre la historia natural de Buffon”. História, Ciências, Saúde - Manguinhos. Vol.20/n. 3, pp. 813-829.

${ }^{7}$ En un principio se afirmó que los fósiles correspondían a especies que habían debido emigrar a zonas inexploradas del globo a raíz de grandes transformaciones climáticas. Sin embargo, la progresiva exploración del planeta tornó cada vez más improbable el hallazgo de rastros de las especies extintas en rincones alejados del mismo. Estas circunstancias llevaron a que, hacia mediados del siglo XVIII, no quedase prácticamente otra opción más que admitir el hecho de que los fósiles correspondían a restos de especies extintas. Cf. Nicholas Kupke. "Caves, fossils and the history of the earth". A. 
Friedrich Wolff. ${ }^{9}$ Pues, todos estos acontecimientos contribuyeron a poner en cuestión la existencia de procesos teleológicos naturales.

Pero la progresiva temporalización de la experiencia natural no sólo tornó problemática la explicación de las formas orgánicas. Más allá de este hecho, que no podemos analizar aquí en toda su extensión, la misma socavó aquellos presupuestos sobre la base de los cuales la estética racionalista de comienzos del siglo XVIII había logrado sostener una concepción secular, pero normativa, de lo bello. ${ }^{10}$ Pues el proceso de temporalización obligaba a limitar las pretensiones nomológicas al ámbito de los fenómenos inorgánicos y tornaba inconcebible, de este modo, aquellas fundamentaciones de la belleza artística que tomaban como punto de referencia la racionalidad intrínseca del orden natural. De hecho, hacia finales del siglo XVIII, la reflexión estética se hallaba obligada a enfrentar una situación de

Cunningham et al. (Eds.) Romanticism and the sciences. New York: Cambridge Univ. Press, 1990, pp. 241-259). Así lo haría Blumenbach, quien señalaba: "cada roca de Göttingen da fe de que especies -incluso géneros enteros- de animales deben haber perecido... las estructuras de un enorme número de fósiles en nuestra vecindad son tan divergentes de las formas presentes que nadie tomaría seriamente ninguna comparación con las formas de vida existente." Johann Friedrich Blumenbarch. Beiträge zur Naturgeschichte. Göttingen: Johann Christian Dieterich, 1790, pp. 6-8.

8 El terremoto de Lisboa de 1755 fue asumido como la refutación definitiva de la tendencia de la teología natural a concebir a la naturaleza como una entidad armónica en la cual podían combinarse la belleza, el orden y la utilidad. Este acontecimiento tornó evidente el hecho de que la naturaleza no podía ser dominada por medio de un orden racional preconcebido y subrayó, además, la finitud de los hombres y su insuperable estado de orfandad. $C f$. Odo Marquard. „Die Krise des Optimismus und die Geburt der Geschichtsphilosophie“. G. Lauer et al. (Eds.) Das Erdbeben von Lissabon und der Katastrophendiskurs im 18. Jahrhundert. Göttingen: Wallstein, 2008, pp. 205-215.

9 Las investigaciones de Wolff ponían en evidencia la existencia de transformaciones morfológicas en el lapso que mediaba entre la fecundación y la formación definitiva del embrión. Wolff remitía estas modificaciones a la diferenciación y sedimentación gradual de un material originariamente indiferenciado Cf. Caspar Friedrich Wolff. Theorie von der Generation in zwei Abhandlungen erklärt und bewiesen. Hildesheim: Robert Herrlinger, 1966, p. 163. De esta forma, las diferentes partes de los cuerpos organizados se presentaban como momentos sucesivos y progresivos del proceso de estructuración de la materia inorgánica que se hallaba disponible en el embrión. No obstante, para que esta interpretación resultase inteligible era necesario dar cuenta de la existencia de una causa que se encontrase en condiciones de producir los fenómenos observados. En este contexto, el embriólogo alemán apelaba a una misteriosa vis essentialis que debía garantizar la unicidad y articulación interna del proceso generativo. Con esto, Wolff no lograba resolver el problema de la generación, pero ponía en evidencia al menos la necesidad de concebir principios explicativos que, a diferencia de las fuerzas mecánicas, fuesen capaces de dar cuenta de la producción de una cadena de estructuras diferenciadas y coordinadas entre sí.

10 En este sentido resulta paradigmático el trabajo de Johann Christoph Gottsched. Gottsched le atribuía a dios la creación de todo "según número, masa y medida" y, asumiendo el carácter bello de la naturaleza, infería de allí la necesidad de una imitación artística de la misma. "Las cosas naturales son bellas en sí mismas y si el arte quiere producir también algo bello, debe imitar el modelo de la naturaleza. La relación exacta, el orden y la armonía correcta de todas las partes, en la que consiste una cosa, es la fuente de toda belleza. La imitación de la naturaleza perfecta puede dar entonces a una obra artística la perfección por medio de la cual aquella guste y resulte agradable para el entendimiento. La desviación con respecto a este modelo, producirá siempre algo informe y contrario al gusto." Johann Christoph Gottsched. Versuch einer Critischen Dichtkunst. Leipzig: Breitkopf, 1751, p. 132. 
carácter paradójico. Pues, de admitir la existencia de leyes naturales para la creación artística, debía renunciar a la posibilidad de concebirlas en términos estéticos, ya que, en un sentido estricto, las formas naturales no se hallaban dotadas de belleza ni de fealdad.

En las páginas que siguen intentaremos revisar algunas de las estrategias por medio de las cuales la reflexión estética de las últimas décadas del siglo XVIII intentó superar la pérdida de legitimidad ontológica de la representación artística a la que dieron lugar los procesos mencionados. Antes que nada, consideraremos los orígenes de la estética ilustrada de los efectos, en tanto primera respuesta a la crisis de la estética racionalista clásica. En segundo lugar, analizaremos el posicionamiento crítico de Johann Gottfried Herder y de Karl Philipp Moritz frente a las perspectivas psicológico-efectuales y, en tercer término, nos concentraremos en la redefinición del concepto de belleza que proponía Immanuel Kant en la Crítica de la facultad de Juzgar. ${ }^{11}$ En este punto resulta de nuestro interés advertir que la concepción estética kantiana de la belleza no solo colocaba a la subjetividad en un lugar central sino que modificaba, a su vez, el estatuto y las funciones del ámbito estético mismo. Con esto hacemos referencia al hecho de que Kant concibiera al placer estético a partir de la forma de un posible funcionamiento coherente de las facultades o disposiciones subjetivas. Puesto que, con este desplazamiento, la filosofía kantiana sentaba las bases sobre las cuales las estéticas idealistas de finales del siglo XVIII y comienzos del XIX articularían la problemática filosófica de la autofundamentación de la subjetividad con el problema de la legitimación estética de la representación artística. ${ }^{12}$ Ya que, aun cuando Kant no llegara a concebir a la belleza artística como auto-objetivación de una subjetividad unificada, convertía a la experiencia estética en un espacio adecuado para apuntalar una posible aplicación extraestética exitosa de las diferentes capacidades subjetivas. ${ }^{13}$ Hasta qué punto se atentaba de

\footnotetext{
11 Asumimos aquí la existencia de una continuidad entre el juicio teleológico y el juicio estético no solo en tanto ambos intentan dar respuesta a un mismo problema - que tiene su origen en el proceso de temporalización- sino también porque lo hacen por medio de un desplazamiento análogo más allá del ámbito de la representación. Una lectura de la obra kantiana que enfatiza, en cambio, las diferencias existentes entre los dos momentos de la Crítica de la facultad de juzgar puede encontrarse en Lewis White Beck y Paul Guyer. Cf. Lewis White Beck. Early German Philosophy. Cambridge: Belknap Press, 1969, pp. 496-498; Paul Guyer. Kant and the Claims of Taste. Cambridge: Harvard Univ. Press, 1979, pp. 213-18. No obstante, estas posturas han sido particularmente discutidas en los últimos años. En este sentido pueden ser consultadas las interpretaciones de Rachel Zuckert y de Hannah Ginsborg. Cf. Rachel Zuckert. Kant on Beauty and Biology. Cambridge: Cambridge Univ. Press, 2007 y Hannah Ginsborg. "Kant on Aesthetic and Biological Purposiveness". Andrews Reath et al. (Eds.) Reclaiming the History of Ethics: Essays for John Rawls. Cambridge: Cambridge Univ. Press, 1997, pp. 329-360.

12 Una lectura opuesta a la que proponemos aquí ha sido desarrollada durantes los años 70 por Rüdiger Bubner. Este autor establece un hiato entre la estética kantiana y las filosofías idealistas de arte. Desde su perspectiva, la estética kantiana se concentraría en la experiencia estética, y no en la obra de arte, y resignaría el contenido de verdad de esta última. $C f$. Rüdiger Bubner. "Über einige Bedingungen gegenwärtiger Ästhetik“. Neue hefte für Philosophie. Göttingen, Vandenhoeck \& Ruprecht, V. 5, 1973, p. 65 ss.

13 En este punto, nuestra interpretación se orienta en un sentido similar al análisis que propone Zuckert. En su estudio sobre la tercera crítica kantiana, la autora sostiene que Kant habría introducido allí una nueva concepción de la subjetividad que tensionaba los márgenes del pensamiento crítico. Según Zuckert, este movimiento respondía a la necesidad de explicar "cómo podemos comprender lo
} 
esta forma contra la autonomía estética, recientemente conquistada, es algo sobre lo cual deberemos reflexionar a partir del recorrido propuesto.

\section{Teleología natural y belleza artística}

En el marco de la crisis epistémica a la que hacíamos referencia más atrás, la reconstrucción del orden natural pasó a depender de la posibilidad de postular un principio o una fuerza oculta que estuviese en condiciones de superar el carácter aparentemente caótico de las formas orgánicas visibles. De hecho, el propio Kant había llegado a sugerir la necesidad de construir una historia de la naturaleza que permitiese ligar la apariencia actual de los seres naturales con sus formas ancestrales y ordenar, de esta forma, la dispersión existente en el mundo natural ${ }^{14}$. Sin embargo, la referencia a este orden natural oculto no fue considerada por Kant como una estrategia adecuada en orden a salvar la legitimidad de la representación artística. A esta alternativa se oponía, antes que nada, la propia imposibilidad epistémica de afirmar el carácter objetivo de aquellas conclusiones a la que arribaba la mentada historia natural. Pues, como era puesto en evidencia en la Crítica de la facultad de juzgar, los resultados de esta última hacían referencia a un ordenamiento natural que no resultaba concebible a partir de ninguna de las formas causales que se hallaban al alcance de nuestra comprensión. Dicho con mayor precisión, la organización profunda de los seres naturales no podía ser deducida a partir de causas mecánicas, ${ }^{15}$ pero tampoco podía ser entendida como el producto de una acción de tipo intencional. ${ }^{16}$ Desde un punto de vista mecánico, el orden

dado empíricamente, lo particular, lo contingente en cuanto tal -esto es, precisamente aquello que es marginal o se halla más allá de las formas universales, de los conceptos o de las leyes de las cuales se ocupa la filosofía kantiana (y muchas otras)." Rachel Zuckert. Op. cit. p. 6. Sin embargo, Zuckert no especifica las condiciones epistémicas que hicieron posible la emergencia del problema de lo particular, es decir, que tornaron insuficientes las respuestas que había formulado la modernidad temprana frente al mismo. Tampoco entra dentro del campo de intereses de la autora el análisis de las consecuencias estéticas que traía aparejada la remisión del placer estético al ideal regulativo de una subjetividad unificada.

14 Immanuel Kant. Kritik der Urteilskraft. Kants gesammelte Schriften. Tomo V. Berlin: Gruyter, 1913, p. 428.

15 Esto es, a diferencia de otros fenómenos naturales, como por ejemplo el movimiento de los astros, la particular articulación de las leyes empíricas que se registraba en los cuerpos orgánicos no podía deducirse a priori a partir de las leyes generales de la naturaleza. "Si se menciona, por ejemplo, la constitución de un pájaro, la concavidad de sus huesos, la posición de las alas para el movimiento y de la cola para maniobrar, entonces se debe asumir que, si uno no se vale de un tipo especial de causalidad, es decir, la de los fines (nexus finalis), todo esto resulta completamente contingente según el mero nexus effectivus de la naturaleza; es decir, que la naturaleza, como mero mecanismo, podría había formado de mil maneras distintas sin dar con la unidad de dicho principio". Ibídem p. 360.

16 Con respecto a este tema, se pueden consultar los trabajos de Hannah Ginsborg y de Eckart Förster. Cf. Hannah Ginsborg. "Two Kinds of Mechanical Inexplicability in Kant and Aristotle. Journal of the History of Philosophy, vol. 42 (1), 2004, pp. 33-39 y Eckart Förster. "Die Bedeutung von §§76, 77 der 'Kritik der Urteilskraft' für die Entwicklung der nachkantischen Philosophie“. Zeitschrift für philosophische Forschung, vol. 56, 2002, pp. 169-190. En ambos casos, la referencia a la imposibilidad de explicar los organismos por medio de un propósito se orienta a discutir la interpretación de la dife- 
de las formas naturales debía ser considerado como un producto azaroso, mientras que si se lo concebía como el resultado de una acción intencional, el mismo dejaba de presentarse como un orden de carácter natural ${ }^{17}$. Esto es, la postulación de una intencionalidad objetiva obligaba a introducir un concepto exterior y anterior con respecto a las partes que componían el orden natural, y esto último tenía como consecuencia la destrucción de la relación de acción recíproca entre las partes y el todo que diferenciaba a los productos orgánicos de los meros objetos de fabricación. 18 Probablemente por este motivo, Kant se vio llevado a definir la aparente "conformidad a fin" del mundo natural a partir de la introducción de principios de carácter estrictamente subjetivo ${ }^{19}$. Desde este punto de vista, la naturaleza podía ser

renciación kantiana entre organismos y máquinas que ofrecen Peter McLaughlin, Henry Allison o Guyer. Cf. Peter McLaughlin. Kant's Critique of Teleology in Biological Explanation: Antinomy and Teleology. New York: Mellen, 1990, p. 153; Henry Allison. "Kant's Antinomy of Teleological Judgment". Southern Journal of Philosophy, supl. 30, 1991, p. 27; Paul Guyer. "Organisms and the Unity of Science". Eric Watkins (Ed.) Kant and the Sciences, p. 264. Oxford: Oxford University Press, 2001 , p. 264. Aunque con algunos matices, los intérpretes mencionados coinciden en reducir dicha diferencia a la imposibilidad/posibilidad de que la totalidad sea explicada en función de la mera interacción de las partes. Como ponen en evidencia Ginsborg y Förster, esta lectura pasa por alto el hecho de que tampoco la explicación de los artefactos es posible a partir del mero análisis de las partes. Estos últimos solo pueden ser comprendidos si se introduce la referencia a un propósito o una intención y este, justamente, el punto en el cual se diferencian de los organismos naturales. Cf. Nota 18.

17 Immanuel Kant. Op. cit. p. 375.

18 Según la lectura de Ginsborg o de Förster, Kant habría definido a los organismos como aquellas entidades en el marco de las cuales las partes no solo se articulaban en función de una totalidad, como sucedía en el caso de un reloj, por ejemplo, sino que establecían entre ellas, además, una relación de acción recíproca: "Un cuerpo que en sí y según su posibilidad interna es juzgado como fin natural exige que sus partes sean producidas mutuamente tanto en lo que concierne a su forma como a su conexión, y que así produzcan un todo a partir de la propia causalidad." Ibidem. p. 373. Como resulta comprensible, esta definición de los organismos en términos de acción recíproca entre las partes y el todo imposibilitaba toda conceptualización de los mismos, en la medida en que eran las partes las que, pese a su dependencia con respecto al todo, debían dar cuenta de la producción del mismo. Si bien Kant asumía la diferencia entre organismos y artefactos como un dato evidente -"Un ser orgánico no es una mera máquina, pues esta tiene solo fuerza motriz, sino que posee en sí fuerza formadora, es decir, una fuerza que él trasmite a materiales que no la tienen (los organiza). Por lo tanto, posee una fuerza se forma y procrea y que no puede ser explicada a partir de la mera capacidad del movimiento (el mecanismo)." Ibid. p. 374 -, resulta necesario recordar aquí que se trataba de una distinción relativamente reciente. De hecho, la misma resultaba dependiente de las investigaciones embriológicas de Wolff a las que hemos hecho mención más arriba. Estas investigaciones llevaron a poner definitivamente en duda la idea de que los organismos hubiesen sido producidos por un plan o idea general de carácter divino al comienzo de los tiempos y obligaron a presuponer la existencia de algún tipo de fuerza inmanente que permitiera explicar la serie articulada de transformaciones que tenían lugar durante el desarrollo del embrión. Kant se hacía eco de tales cambios epistémicos al afirmar en la Crítica de la facultad de juzgar: "Se dice demasiado poco de la naturaleza y de su capacidad en los productos organizados si se los piensa por medio de la analogía con el arte. Pues entonces se piensa a un artista (un ser inteligente), fuera de ella. Pero la naturaleza se organiza ella misma y lo hace ciertamente en cada especie de sus productos organizados... Quizás uno se acerca más a esta característica insondable si la denomina un análogo de la vida." Ibid. p. 374.

19 Ibid. p. 182. 
contemplada como un producto del arte, pero solo en tanto se recordara que la perspectiva así ganada era el resultado de conjeturas y suposiciones que, pese a su urgencia subjetiva, no encontraban correlato alguno en el mundo natural. 20

Pero el posicionamiento de Kant con respecto al problema del orden natural no solo lo obligaba a renunciar a la posibilidad de pensar en una estética de carácter mimético sino que le impedía, además, reemplazar aquella dimensión ontológica por medio de la propia representación artística. En este punto, las observaciones kantianas afectaban a tendencias tales como el Sturm und Drang o el clasicismo de Weimar, que, desde Alexander G. Baumgarten en adelante, habían procurado garantizar el valor de verdad de la esfera estética frente a las estéticas de carácter efectual. ${ }^{21}$ En un primer momento, aquellas tendencias habían perseguido fines eminentemente estéticos en la medida en que habían intentado superar la relativización de los juicios estéticos a la que conducía el abordaje psicológico-efectual. Sin embargo, en su búsqueda de una legitimación alternativa para el ámbito estético, las perspectivas de finales del siglo XVIII acabaron dando lugar a una concepción de la representación artística que descargaba sobre ella funciones de carácter filosófico. ${ }^{22}$ Dicho en pocas

20 No podemos analizar aquí con detenimiento el conjunto de problemas provenientes de la historia natural clásica al que procuraba dar respuesta la propuesta kantiana de un uso regulativo de principios teleológicos. Concretamente la pretensión kantiana de considerar a la naturaleza como si la misma procediese de acuerdo a determinada finalidad se hallaba orientada a conjurar el fantasma de los cambios morfológicos de carácter irreversible. Esto puede observarse con claridad en el tratamiento kantiano del problema de las razas. Pues, por medio de la idea de disposiciones germinales que se activaban de manera selectiva, Kant lograba retrotraer a los orígenes la totalidad de las transformaciones temporales que habían dado lugar a las diferentes razas de la especie humana. Para este tema, es necesario recurrir tanto a los escritos precríticos de Kant como a los nuevos análisis del problema que propone el autor desde mediados de los años 80. Cf. Immanuel Kant. "Von den verschiedenen Rassen der Menschen“. Kants gesammelte Schriften. Tomo II. Berlin: Gruyter, 1912, pp. 427-443; „Bestimmung des Begriffs einer Menschenrasse“. Kants gesammelte Schriften. Tomo VIII, Berlin: Gruyter, 1923, pp. 89-106; „Über den Gebrauch teleologischer Principien in der Philosophie. Kants gesammelte Schriften “. Tomo VIII, Berlin: Gruyter, 1923, pp. 157-184.

21 En Baumgarten esta tendencia se presentaba con cierta ambigüedad. Por una parte, Baumgarten encabezaba la reacción a la estética de escuela de Gottsched, que pretendía sostener aún el principio de la imitación. En este sentido, tanto Baumgarten como Johann J. Bodmer y Johann J. Breitinger enfatizaban el momento sensible de lo bello contra la focalización de Gottsched en la imitación de la naturaleza. $C f$. Dieter Kliche. "Ästhetik“. Karlheinz Barck et al. (Eds.) Ästhetische Grundbegriffe Historisches Wörterbuch in sieben. Tomo I. Stuttgart/Weimar: Metzler, 2010, p. 331. Pero, por otra parte, Baumgarten llamaba la atención acerca del hecho de que la sensibilidad, a diferencia del entendimiento disociador, tenía que ver con representaciones en las cuales la experiencia se presentaba de manera unificada. En este sentido, la apariencia estética permitía hacer presente el todo del mundo en la medida en que la misma se hallaba organizada a partir de una conexión interna. Su rendimiento era así la fundamentación de la unidad. Cf. Eberhard Ostermann. Das Fragment. Geschichte einer ästhetischen Idee. München: Wilhelm Fink, 1991, pp. 26-7.

22 Joachim Ritter concibe estas funciones en términos compensatorios al interpretar el surgimiento de la estética y de la autonomía del arte como una respuesta a la pérdida de realidad a la que condujo el proceso moderno de objetivación de la naturaleza. A partir este proceso, la realidad dejaba de presentarse como un cosmos y el arte asumía la tarea de revivir el lenguaje extinguido del mismo. El surgimiento de este interés en el ámbito de la estética es descripto por Ritter en los siguientes términos: 
palabras, las nuevas tendencias estéticas colocaban a la propia dimensión artística en el lugar de la antigua naturaleza perdida. Puesto que legitimaban la representación artística por medio de cualidades que la convertían de suyo en una instancia capaz de superar la contingencia $^{23}$ a la que había conducido la crisis de la historia natural.

\section{La obra de arte como naturaleza}

La apreciación con la que concluimos el parágrafo anterior resulta comprensible si se tiene en cuenta hasta qué punto la crisis de la historia natural clásica privó a la representación artística de aquel objeto en relación con el cual la misma había definido su valor y legitimado su existencia. De hecho, con la temporalización de las formas naturales y el desmoronamiento del acuerdo preformista entre causalidad mecánica y final, se tornó necesaria una completa redefinición del concepto de belleza. Pues, a partir de tales transformaciones epistémicas dejaba de ser posible identificar la belleza con ciertas propiedades de carácter objetivo y se volvía inminente el giro de la reflexión estética hacia el ámbito de la subjetividad. Este hecho, que fue puesto en evidencia de manera paradigmática por David Hume, tuvo como resultado la invención de la estética, en tanto disciplina independiente, y el florecimiento de las perspectivas psicológico-efectuales. En consonancia con la propia definición baumgarteniana de la estética como ciencia del conocimiento sensible ${ }^{24}$, las teorías efectuales procuraron sustituir la referencia de la obra a la belle nature por un análisis de carácter psicológico. En este sentido, afirmaba Friedrich Just Riedel que lo bello no era una característica intrínseca de las cosas que se llamarían bellas: "A diferencia de la perfección, la belleza no les corresponden de por sí a los objetos contemplados, sin relación a una enti-

"Baumgarten adhiere a la definición de Chr. Wolff, según la cual lo bello es lo que place (quod placet dicitur pulchrum). Pero Baumgarten amplía a su vez la estética como teoría del arte bello y la transforma en "ciencia de lo bello". Lo que se hace presente de manera subjetiva en el bello pensamiento, es el mundo en su perfección (perfectio)”. Joachim Ritter. „Ästhetik, ästhetisch“. Joachim Ritter at al. (Eds.) Historisches Wörterbuch der Philosophie. Tomo I. Darmstadt: Wissenschaftliche Buchgesellschaft, 1971, p. 569. En el contexto de la metafísica de Baumgarten, la perfección designaba la armonía y el orden en la composición de las partes que hacían posible la comprensión del mundo como aquella unidad por medio de la cual dios daba a conocer su perfección. Ritter atribuye un sentido positivo a esta compensación por la unidad perdida entre el sujeto y el mundo que se da en el terreno artístico en la medida en que el autor sostiene la necesidad del proceso de modernización. Como Schiller, Ritter considera: "que la escisión... no sólo es corregible estéticamente sino también una condición necesaria y persistente de la cultura" y que "no es adecuado que la sociedad existente de las necesidades y de la utilidad se interrumpa en algún momento". Ibídem pp. 568s.

23 El término contingencia remite, en este contexto, a "un modo deficitario de sentido, coherencia y orden final" que es caracterizado "en función de determinaciones negativas como no necesidad, irregularidad, dependencia, fugacidad, mensurabilidad, previsibilidad." Werner Frick. Providenz und Kontingenz. Untersuchungen zur Schicksalssemantik im deutschen und europäischen Roman des 17. und 18. Jahrhunderts I. Tübingen: Niemeyer, 1988, p. 11.

24 Alexander G. Baumgarten. Aesthetica, Hildesheim: Georg Olms, 1970, par. 14; Cf. Ma. Jesús Soto Bruna. "La Aesthetica de Baumgarten y sus antecedentes leibnicianos". Anuario Filosófico, vol. 20, 1987, pp. 181-190. 
dad que los percibe. La belleza es de naturaleza relativa y solo una relación en la cual algo nos gusta." 25

En un primer momento esta nueva perspectiva fue duramente criticada por la antigua estética de escuela, la cual acusaba a las tendencias efectuales de incorporar al ámbito artístico elementos que resultaban irreductibles a la dimensión racional -esto es, elementos tales como la expresión, la sensibilidad o la imaginación. En este sentido, al presentar su traducción de Las artes reducidas a un único principio (1754) de Batteaux, Johann Christoph Gottsched señalaba que la difusión de esta obra se hallaba orientada a combatir "la corriente de doctrinas equivocadas que no quieren buscar la naturaleza del arte poético en la imitación, sino en las meras expresiones salvajes de una imaginación sin reglas, que llaman estética."26

Pero no fueron estas las únicas críticas de las que fueron objeto los nuevos desarrollos de la estética efectual. Pues, también las generaciones más jóvenes miraron con desagrado las tendencias instrumentales que se hallaban contenidas en la consideración de la representación artística desde el punto de vista del espectador. Para tales perspectivas, ya no era la confusión que introducía el primado de la imaginación lo que resultaba preocupante, sino más bien la posibilidad de rebajar las formas artísticas al estatuto de entretenimiento o de reorientarlas hacia una formación de carácter moral. Sin embargo, las nuevas perspectivas estéticas ya no contaban con ninguna referencia externa a la hora de fundamentar la relevancia de la esfera estética. Por este motivo, las mismas debieron concentrarse en los momentos no miméticos de la representación artística a los fines de sostener la amenazada artisticidad de la representación artística. En este sentido es posible leer tanto la tendencia del Sturm und Drang a enfatizar el carácter poiético de la creación artística como la focalización del clasicismo de Weimar en los aspectos formales de la representación artística.

En esta oportunidad no podemos analizar con detenimiento la significación históricofilosófica que asumió el arte en tanto expresión de una naturaleza de carácter poiético o productivo. Al respecto, baste realizar aquí una breve referencia al particular empleo de las teorías antipreformistas que es posible encontrar en el marco de la obra temprana de Herder. Dicho en pocas palabras, las nuevas concepciones del fenómeno de la generación -tales como las de Wolff- le ofrecieron al joven filósofo un modelo adecuado a los fines de dar cuenta tanto de la objetividad de la representación artística como de las consecuencias estéticas del proceso de temporalización 27 . Por medio de la referencia a una naturaleza de carácter productivo, Herder podía desechar aquellas interpretaciones clasicistas que establecían un lazo estático y representativo entre las formas artísticas y la apariencia visible de la naturaleza devenida. Puesto que, así consideradas, estas últimas asumían un carácter secundario o meramente superficial, mientras que las formas artísticas originales se presentaban como

\footnotetext{
25 Friedrich Just Riedel. Philosophische Bibliothek. Tomo 1. Wien/Jena: Gebauer, 1769, p. 116.

26 Johann Christoph Gottsched. Das Neueste aus der anmuthigen Gelehrsamkeit (Auszug aus der Herrn Batteux schönen Künsten aus dem einzigen Grundsatze der Nachahmung), Leipzig: Breithopf, 1754, p. 464.

27 Cf. John H. Zammito. „Herder, Kant, Spinoza und die Ursprünge des deutschen Idealismus“. Herder und die Philosophie des deutschen Idealismus. Marion Heinz. (Ed.) Amsterdam y Atlanta: Rodopi, 1997, pp. 107-145; John H. Zammito. The Genesis of Kant's Critique of Judgment. Chicago: University of Chicago Press, 1992, pp. 189-99.
} 
expresión directa de la propia instancia productiva. Al igual que las formas orgánicas naturales, ellas eran "miembros de este cuerpo y todos los caracteres y modos de pensar, rasgos para este espíritu." 28

De esta manera, era posible resguardar la verdad de la representación artística y garantizar, a su vez, la irreductibilidad de las obras particulares a criterios normativos generales. Puesto, liberado de las reglas abstractas y superficiales de la poética clásica y de toda mediación de naturaleza reflexiva, el sentimiento del artista enlazaba de manera inmediata con la plasticidad infinita del principio originario: “¡Afortunado hijo de los dioses por su empresa! -señala Herder refiriéndose a Shakespeare- ¡Precisamente lo nuevo, lo primero, lo totalmente distinto demuestra la fuerza primitiva de su vocación!"29 Sin embargo, no solo se aseguraba de esta forma el estatuto ontológico de la representación artística. Pues, al invertir la relación clasicista entre arte y naturaleza, para transformar a esta última en una instancia de carácter productivo, Herder dotaba a la creación artística de una significación filosófica de carácter singular. Ya que, en tanto manifestación directa de una fuerza genética originaria, la esfera artística hacía presente en la historia el recuerdo vivo de una antigua naturaleza perdida.

Pero no solo Herder convirtió a la representación artística en un recurso adecuado a las fines de superar la experiencia moderna de la contingencia. Ya que también el intento clasicista por depurar a los aspectos formales de la obra de arte de su carácter instrumental -y por ende relativo-, ubicó a estos últimos al límite de su existencia sensible y dio lugar, de esta forma, a una metafísica de la obra de arte autónoma. Esta última tendencia alcanzó su máxima expresión en el pensamiento de Moritz quien, en "Über den Begriff des in sich selbst Vollendeten", contraponía el valor relativo de los objetos útiles al carácter absoluto de los objetos bellos. En clara referencia a las estéticas efectuales, Moritz señalaba allí:

El objeto meramente útil no es un todo o algo en sí mismo completo, sino que lo llega a ser recién cuando alcanza su fin en mí o se completa en mí. Pero en la contemplación de lo bello, saco el fin de mí y lo coloco en el objeto mismo: lo contemplo como algo que no se completa en mí, sino que es en sí mismo completo; como algo, por ende que constituye en sí mismo un todo y me concede placer en aras de sí mismo. 30

Como puede constatarse a partir del pasaje citado, la autonomización de la obra de arte con respecto a toda posible utilidad o referencia subjetiva se ofrecía, para Moritz, como una estrategia adecuada para sostener la dignidad de la belleza en un contexto en el cual la totalidad de los fines concebibles habían devenido relativos. Puesto que la contraposición entre lo bello y lo útil permitía desligar las cualidades estético-representativas de toda perspecti-

28 Johann Gottfried Herder. Shakespeare. Trad. Juan Probst Universidad Nacional de Buenos Aires. Facultad de Filosofía y Letras. Instituto de Literatura Anglogermánica, Buenos Aires, 1949, p. 41. El interés de Herder por las nuevas ciencias naturales se acentúa algunos años más tarde, en el marco de Ideas. Cf. Johann Gottfried Herder. Ideen zur Philosophie der Geschichte der Menschheit. Ed. W. Pross. München/Wien: Carl Hanser, 2002, pp. 172 /4.

${ }^{29}$ Herder, Johann Gottfried. Shakespeare. Op. Cit., p. 25.

30 Karl Philipp Moritz. Schriften zur Ästhetik und Poetik. Kritische Aufgaben. Tübingen: Walter de Gruyter, 1962, p. 3. 
va mimética sin renunciar, por ello, al carácter absoluto de las mismas. Esto es, la consideración de la obra de arte como "conformidad a fin interna" 31 ofrecía la posibilidad de fundamentar la objetividad de la representación artística en su propia independencia estructural. Ya que, a diferencia de los artefactos, la estructura interna de la obra arte no resultaba dependiente de un concepto que preexistiese a la propia instancia de la representación. ${ }^{32}$ Entre las partes y el todo se establecía así una relación de acción recíproca, de tal manera que la perfección de la obra ya no se desprendía de finalidades externas y podía ser considerada, en este sentido, de carácter absoluto.

Ahora bien, por medio de la identificación de la estructura de la obra con la consumación interna (in sich selbst vollendet), Moritz lograba atribuirle a la representación artística una función mediadora entre el hombre y la naturaleza y concederle, así, no solo un valor artístico sino también una significación particular de carácter filosófico. Pues en tanto totalidad cerrada sobre sí misma, la obra de arte se presentaba como una imagen sensible "del gran todo de la naturaleza que nos circundaba"; el cual, pese a "tener en sí mismo su fin final y existir para su propia gloria", no resultaba inmediatamente perceptible para nosotros. En este contexto, la determinación de la obra en tanto consumación interna permitía liberar a las formas naturales de su contingencia empírica -la Hülle der Existenz, según afirma Moritz en "Über die bildende Nachahmung des Schönen"33- e integrarlas en una totalidad inmediatamente visible que, en cuanto tal, se convertía en un medio capaz de incentivar nuestro sentido para la totalidad. "Considerado de esta forma", concluía Moritz en "Bestimmung des Zwecks einer Theorie der schönen Künste", lo bello "puede ser verdaderamente útil en la medida en que afina nuestra capacidad de percepción del orden y la armonía y eleva nuestro espíritu por sobre las pequeñeces porque ella nos permite mirar claramente todo en el todo y en relación al todo."34 La obra de arte, señalaba Moritz en "Über die bildende Nachahmung des Schönen", "puede reflejar libremente las relaciones del gran

\section{Ibidem p. 6.}

32 A los fines de explicar esta idea, Moritz recurría a la mitología antigua. Haciendo un uso despectivo del término alegoría, Moritz había cuestionado en 1791 la tendencia a interpretar las figuras mitológicas como meras representaciones figurativas de conceptos abstractos y generales. Del mismo modo en que en el terreno de la fantasía, señalaba Moritz, Júpiter significaba simplemente Júpiter, las obras de arte verdaderas no podían significar algo que se encontrase más allá de sí mismas. Ellas "son algo acabado y perfecto en sí mismo, que existe por su propia voluntad, y cuyo valor radica en sí mismo y en la relación armónica de sus partes" y no, como pretendía la decadente tradición del arte moderno, un conglomerado de elementos sensibles que servía de ocasión para la manifestación de un pensamiento de carácter conceptual. De ser así, las obras se asimilarían a meros jeroglíficos o letras de imprenta que "pueden estar conformados como quieran, siempre y cuando designen aquello en lo que haya de pensarse", como sostiene Moritz en "Götterlehre oder Mythologische Dichtungen der Alten". Ibid. p. 196.

33 Ibid. p. 74. En "Die metaphysische Schönheitslinie" Moritz concretiza esta idea en los siguientes términos: "el poeta corta los hilos por medio de los cuales los acontecimientos podrían tener una inclinación más allá de sí, él omite lo que interviene en otra esfera de los acontecimiento, reúne causa y efecto como si ellas estuvieran en el curso habitual de las cosas. Vemos reunidos en un breve espacio de tiempo, una multiplicidad de acontecimientos que se suceden, que suceden a lo largo de siglos." Ibid. p.153.

34 Ibid. p. 122. 
todo de la naturaleza en su completa extensión" 35 y "comprende en sí todo lo que la realidad hubiera debido destruir si ella no hubiese tenido el poder de desprenderlo de sí y presentarlo fuera de sí de manera figurativa."36

\section{El escepticismo estético kantiano}

La desconfianza de Kant con respecto a los proyectos estético-culturales mencionados hasta aquí remitía a motivos similares a los que habían resultado determinantes a la hora de rechazar la existencia de una intencionalidad objetiva en el plano natural. ${ }^{37}$ Desde el punto de vista kantiano, la "conformidad a fin" de las formas artísticas solo podía ser explicada en términos objetivos a partir de la postulación de una subjetividad creadora que dispusiera las partes en función de un fin preconcebido. Pero entonces, señalaba Kant, ya no era posible establecer una distinción entre las obras de arte y los demás productos del arte humano puesto que en ambas oportunidades se establecía una articulación de las partes y el todo que respondía a un concepto preexistente con respecto a los propios elementos constitutivos. Esto es, en tanto productos intencionales, las obra de arte debían ser juzgadas en función de objetivos externos a la instancia de la representación y de acuerdo con procedimientos similares a aquellos que eran utilizados en el caso de los artefactos mecánicos. Un juicio semejante, sin embargo, solo podía remitir a la posible utilidad o perfección de las obras de arte y carecía de interés en el momento de establecer el valor específicamente estético de las mismas. ${ }^{38}$

Ciertamente, existía la posibilidad de neutralizar la intencionalidad subjetiva por medio de su remisión a la fuerza productiva natural. Esto era lo que había hecho en cierta forma el propio Moritz, por medio de la "teoría del genio"39, y antes que él, el joven Herder y los demás integrantes del Sturm und Drang. Sin embargo, dicha estrategia no hacía más que

\footnotetext{
35 Ibid. p. 77.

36 Ibid. p. 90.

37 Kant había negado ya en la Crítica de la razón pura (1781) la posibilidad de una ciencia de lo bello: "Los alemanes son los únicos que emplean hoy la palabra estética para designar lo que otros denominan crítica del gusto. Tal empleo se basa en una equivocada esperanza concebida por el destacado crítico Baumgarten. Esta esperanza consistía en reducir la consideración crítica de lo bello a principios racionales y en elevar al rango de ciencia las reglas de dicha consideración crítica. Pero este empeño es vano, ya que las mencionadas reglas o criterios son, de acuerdo con sus fuentes, meramente empíricas y, consiguientemente, jamás pueden servir para establecer leyes a priori por las que debería regirse nuestro juicio del gusto." Immanuel Kant. Crítica de la razón pura. Trad. Ribas, P. Madrid: Alfaguara, 1998, A 22/ B36. Sin embargo, un tratamiento acabado del problema se haría esperar hasta la publicación de la Crítica de la facultad de juzgar. También es establecida en la Crítica de la razón pura la distinción fundamental entre estética en el sentido de teoría de la sensibilidad y estética en el sentido de crítica del gusto. Cf. Ibídem A 21/ B35/6.

38 De este punto de vista, no solo se cerraba la posibilidad de remitir el placer que deparaba el arte al objeto imitado sino también de interpretarlo como el resultado de carácter técnicamente logrado de la imitación. $C f$. Dieter Henrich. „Kunst und Natur in der idealistischen Ästhetik“. H. Robert Jauß (Ed.) Nachahmung und Ilussion. München: Wilhelm Fink, 1969, p. 129.

39 Moritz postulaba la existencia de una fuerza activa (tätige Kraft o Tatkraft) que subyacía tanto a la imaginación como a la sensibilidad estética. Karl Philipp Moritz. Op. Cit. pp. 75-87.
} 
proyectar el problema más atrás, puesto que entonces era necesario dar cuenta del modo en que la propia naturaleza producía "conforme a fin". Desde el punto de vista de Kant, Herder simplemente evadía este problema por medio de la identificación de la naturaleza con una fuerza generativa que era capaz de manifestarse en infinitas formas singulares. Pues, una perspectiva semejante introducía una serie de supuestos que frustraban el uso normal de nuestras facultades cognitivas y que reubicaban al hombre en el marco del orden natural.

La primera de estas consecuencias se seguía, según sostenía Kant en su reseña de Ideas, de la plasticidad infinita que le era atribuida por Herder a la fuerza genética originaria. Pues, una vez asumida la existencia de una fuerza que era capaz de intervenir de manera directa en el ámbito de la historia, ya no resultaba posible sostener la necesidad de las clasificaciones científicas de los seres naturales ni asegurar la racionalidad intrínseca del mundo natu$\mathrm{ral}^{40}$. En este registro es posible leer la afirmación kantiana con respecto a la conveniencia de limitar el poder creativo de la fuerza genética originaria:

si la causa que organiza desde dentro estuviera limitada por su naturaleza a un cierto número y grado de diferencias en el desarrollo de su criatura (organización según la cual dicha causa no sería libre para modelar conforme a otro patrón en caso de modificarse las circunstancias), podría denominarse a esta determinación natural de la naturaleza configuradora de "gérmenes" o "disposiciones originarias", sin considerar por ello a los primeros como dispositivos colocados en un principio que solo se despliegan por casualidad y aisladamente cual capullos (como en el sistema de la evolución), sino como meras limitaciones inexplicables de una facultad autoconfiguradora que tampoco podríamos explicar o hacer comprensible. 41

Sin embargo, la concepción herderiana de la naturaleza no solo abandonaba el mundo natural al imperio de fuerzas irracionales sino que tendía a negar, además, la independencia del juicio moral con respecto a las determinaciones naturales. ${ }^{42}$ Por cierto, no se trataba aquí

40 Elías Palti. Op. cit; John H. Zammito. „Herder, Kant, Spinoza und die Ursprünge des deutschen Idealismus“. Op. Cit. pp. $107-145$.

41 Cf. Immanuel Kant. „Recensionen von J.G. Herders Ideen zur Philosophie der Geschichte der Menschheit". Kants gesammelte Schriften. Tomo VIII. Berlin: Walter de Gruyter, 1923, pp. 62-3 (Utilizo la traducción de Roldan Panadero, Concha y Rodríguez Aramayo, Roberto. $C f$. Kant, Immanuel. "Recensiones sobre la obra de Herder Ideas para una filosofía de la historia de la humanidad". Ideas para una historia universal en clave cosmopolita y otros escritos sobre Filosofia de la Historia. Madrid: Tecnos, 1994, p. 51-2). También en Sobre el uso de principios teleológicos Kant criticaba esta tendencia a unificar aquellas fuerzas que gozaban de algún tipo de correlato empírico en una fuerza general: "Algunos han creído que tenía que suponerse una única fuerza fundamental para explicar la unidad de la sustancia e incluso han pretendido conocerla tan solo con nombrarla con el título común de diversas fuerzas fundamentales...” Immanuel Kant. „Über den Gebrauch teleologischer Principien in der Philosophie“. Op. cit. p. 180 (Utilizo la traducción de Sánchez Madrid, Nuria. $C f$. Kant, Immanuel. "Sobre el uso de principios teleológicos en la filosofía". Logos. Anales del Seminario de Metafisica. Vol. 37 (2004), pp. 7-47, p. 27). El pasaje se aplica perfectamente a la idea de fuerza generativa de Herder. Sin embargo, es posible suponer que el mismo se dirigía en verdad a cuestionar la teoría de la Representación de Reinhold, en la medida en que la misma reducía las fuerzas del alma a "la fuerza de representación del mundo."

42 Con respecto a la discusión que Kant sostuvo con Herder en torno a la posibilidad de una "historia natural de la humanidad", se puede consultar Manfred Riedel. $C f$. Manfred Riedel. "Historizismus und 
de que Herder postulase una concepción materialista de la historia ni del hecho de que el mismo redujese al hombre a su dimensión material. De hecho, su perspectiva histórica y antropológica se hallaba atravesada, más bien, por una fuerte tendencia hacia la espiritualización de la totalidad de las disposiciones y fuerzas naturales. Sin embargo, justamente por este hecho, Herder interpretaba el devenir histórico como manifestación de una fuerza trashistórica y clausuraba, de esta forma, la posibilidad de acciones humanas que encontraran su fundamento en la incondicionalidad de la buena voluntad.

Pero si la identificación de la historia empírica de la naturaleza con su historia en un sentido metafísico privaba de fundamento al conocimiento científico y anula la posibilidad de una moral de carácter prescriptivo, el simple abandono del concepto de lo bello tenía también su precio. Puesto que suponía la renuncia a la única experiencia que parecía confirmar la posibilidad de una aplicación concreta de las diversas fuerzas subjetivas. ${ }^{43}$ Pues, dejando de lado el problema de la racionalidad práctico-moral y limitándonos aquí al ámbito teórico, ¿no se derivaba el placer estético del misterioso acuerdo entre lo particular y lo general que era posible encontrar en ciertas configuraciones artísticas o naturales? Y este acuerdo inexplicable, ¿no alentaba enormes expectativas con respecto a la posibilidad de una concordancia secreta entre nuestras capacidades cognitivas y la disposición efectiva de las formas naturales? Más aun, ¿no indicaba la bella apariencia, en el caso de la belleza natural, la "disposición a fin" de la naturaleza en su conjunto?

Como es sabido, Kant no planteó de manera explícita ninguna de estas preguntas ni se expresó a favor de la necesidad de incorporar un suplemento para el correcto funcionamiento del sistema crítico. No obstante, algunos indicios permiten suponer que el filósofo crítico advertía hasta qué punto el ejercicio efectivo de las facultades humanas, que habían sido descriptas en las dos primeras críticas, solo resultaba concebible si se demostraba la posibilidad de un acuerdo profundo entre las mismas. En este sentido, sería posible pensar que el abordaje del problema de la belleza, que emprendía Kant en el marco de la tercera crítica, encontraba su punto de partida en el reconocimiento implícito tanto de la necesidad de asegurar las condiciones del normal funcionamiento del juicio como de la imposibilidad de hacerlo dentro de los límites del pensamiento crítico. ${ }^{44}$ Desde esta perspectiva, de lo que

Kritizismus. Kants Streit mit G. Forster und J.G. Herder“. Urteilskraft und Vernunft. Kants ursprüngliche Fragestellung. Frankfurt am Main: Suhrkamp, 1989, pp. 148-170.

43 Un análisis semejante podría realizarse también en lo que respecta a los fines morales. Menke estudia este problema a partir del concepto de lo sublime. $C f$. Christoph Menke. "Subjektivität". Karlheinz Barck et al. (Eds.) Ästhetische Grundbegriffe Historisches Wörterbuch in sieben. Tomo V. Stuttgart/Weimar: Metzler, 2010, pp. 760s.

44 Cf. Ibídem pp. 760s. Un análisis levemente más radical presenta Szczepanski. Para este autor, el recurso a lo bello sería una muestra del fracaso del proyecto crítico en tanto que la necesidad de lo bello se desprendería de la incapacidad de la razón para fundar algo positivo en su relación crítica consigo misma. Cf. Jens Szczepanski. Subjektivität und Ästhetik. Gegendiskurse zur Metaphysik des Subjekts im ästhetischen Denken bei Schlegel, Nietzsche und de Man. Bielefeld: Transcript, 2007, p. 104. A partir de aquí, la empresa crítica se transformaría en el intento por reglar de manera racional el acceso racionalmente necesario a lo suprasensible. En este hecho podría vislumbrarse la posición intermedia que ocupa Kant entre la temprana modernidad y el idealismo. Pues, el funcionamiento de la razón kantiana resultaría dependiente de un reaseguro externo, como en el caso de los gérmenes preformados. Sin embargo, también Kant procuraría por momentos ir más allá de esta solución de com- 
se trataba era de determinar en qué medida la idea de Moritz de una finalidad sin fin podía ser vinculada a la revitalización de las fuerzas del ánimo que, según la tradición estéticoefectual, tenía lugar en el marco de la experiencia estética. Pues, si esto era posible, también era factible interpretar el placer que deparaba la contemplación de lo bello como un indicio a favor de la "disposición a fin" de nuestras diversas capacidades cognitivas, sin que fuese necesario presuponer para ello la existencia de entidades bellas, que pudiesen poner en peligro la totalidad del edificio crítico. 45

Reconstruir en detalle el análisis que realizaría Kant del juicio estético no se encuentra dentro de los objetivos fijados en este trabajo. Al respecto, nos limitamos a llamar la atención aquí acerca de papel fundamental que desempeñaba en este contexto el concepto kantiano de "juicio reflexionante". Pues, era justamente este tipo de juicios el que le permitía a Kant vincular el placer estético con la idea de una experiencia en la cual el sujeto se volvía capaz de experimentarse a sí mismo como poseedor de facultades efectivamente cognitivas. ${ }^{46} \mathrm{La}$ argumentación de Kant en este punto consistía en mostrar que aquello que expe-

promiso con el mundo teológico y garantizar así la autofundación de la razón. Desde otra perspectiva, también Ginsborg y Zuckert reconocen la función central que desempeña el principio a priori del juicio reflexionante en el marco del pensamiento crítico. Cf. Hannah Ginsborg. The role of taste in Kant's Theory of cognition. New York: Garland, 1990, cap. 4; Rachel Zuckert. Kant on Beauty and Biology. $O p$. Cit.. Béatrice Longuenesse radicaliza esta postura en tanto sostiene que la propia aplicación de las categorías es inseparable de un proceso que tiene un aspecto reflexivo. $C f$. Béatrice Longuenesse. Kant and the Capacity to Judge. Trad. Charles T. Wolfe. Princeton/Oxford: Princeton University Press, 2000 , pp. 163s. Una posición contraria con respecto a este tema, puede encontrarse en Guyer. Guyer considera menor la relevancia cognitiva del principio de la conformidad a fin y sostiene que el mismo provee más bien una motivación racional en orden a alcanzar la sistematización de la naturaleza. $C f$. Paul Guyer. Kant and the Claims of Taste. Op. cit. p. 57.

45 En este contexto puede explicarse la negativa de Kant a admitir la existencia de una ciencia de lo bello: "No hay ni una ciencia de lo bello, sino tan solo una crítica, ni una ciencia bella, sino tan solo arte bello". Immanuel Kant. Kritik der Urteilskraft. Op. cit., p. 304. Kant llegaba a esta conclusión una vez que comprobaba la imposibilidad de determinar conceptualmente la constitución de los objetos que nos resultan bellos: "No puede haber ninguna regla objetiva de gusto que determine por medio des conceptos lo que es bello. Pues todo juicio que surja a partir de allí es estético, es decir, su fundamento es el sentimiento del sujeto y no el concepto de un objeto. Buscar un principio del gusto, que fije por medio de conceptos determinados el criterio general de lo bello, es un esfuerzo infructuoso." Ibídem p. 231. "Por un principio del gusto se entendería un principio bajo cuya condición se pudiera subsumir el concepto de un objeto y extraer así la conclusión de que es bello". Ibid. p. 285.

46 En este contexto devienen significativos los esfuerzos de Kant por rechazar el relativismo estético aun cuando el mismo no admitiese la existencia de un principio objetivo de juicio. "Si los juicios de gusto tuviesen (al igual que los juicios de conocimiento) un principio objetivo determinado, entonces aquel que realizara tales juicios según este principio podría tener pretensiones de que su juicio fuese incondicionalmente necesario. Pero si los juicios de gusto carecieran de todo tipo de principio, como los meros juicios de los sentidos, entonces, no se podría pensar ninguna necesidad de los mismos. Por lo tanto, ellos deben tener un principio subjetivo que, solo por medio del sentimiento y no de los conceptos, pero con validez general, determine qué gusta y que no." Ibid. p. 237. Sobre la importancia que adquiere en este punto la ejercitación, en tanto mecanismo de disciplinamiento de las fuerzas humanas se puede consultar el posicionamiento de Menke. $C f$. Christoph Menke. Estética y negatividad. Trad. Gustavo Leyva. Buenos Aires: FCE, 2011, pp. 87s y 271s; Christoph Menke. Kraft, Frankfurt: Suhrkamp, 2008, p. 88. 
rimentábamos con placer durante la experiencia estética era la libre concordancia, es decir, la concordancia sin concepto, entre la imaginación y el entendimiento, ${ }^{47}$ para identificar luego esta concordancia con la condición subjetiva de todo conocimiento posible. Se trataba, sostenía Kant, de aquel estado de ánimo en el cual se establecía una relación tal entre las fuerzas representativas que "estas remit[ían] una representación dada al conocimiento en general."48

De esta manera, Kant podía continuar definiendo la belleza, como ya lo había hecho Moritz, en términos de finalidad sin fin. ${ }^{49}$ Sin embargo, lo que dicha expresión mentaba no era ya la existencia de un objeto efectivamente autónomo -la obra de arte-, sino más bien aquel armonioso juego que, en ausencia de todo concepto, se establecía entre las facultades cognoscitivas durante la contemplación de determinados objetos. ${ }^{50}$ De esta forma, se salva-

47 La diferencia entre juicio determinante y reflexionante consiste en que, en el primer caso, la imaginación forma una imagen sensible que unifica las representaciones de los elementos percibidos determinándolas por medio de una regla que corresponde a un concepto determinado. Durante la percepción habitual de objetos, uno se considera determinado por una regla general y esta relación con una regla general basta para explicar el acuerdo entre entendimiento e imaginación. En el caso del juicio estético, no existe ni un concepto ni una regla que guíe la actividad de la imaginación y sin embargo se produce el acuerdo de las facultades en la medida en que, el objeto en virtud de su estructura y disposición no se presenta como un producto de carácter contingente. No es posible determinar un concepto como causa de posibilidad del objeto, pero la apariencia del mismo se presenta no obstante como conforme a fin. Cf. Hannah Ginsborg. Op. Cit. pp. 45-97.

48 Immanuel Kant. Op. Cit. p. 217. "La condición subjetiva de todos los juicios es la propia capacidad para juzgar, o la facultad de juzgar. En vista a una representación por medio de la cual es dado un objeto, aquella utiliza, exige, el acuerdo de dos facultades representativas: esto es, de la imaginación (para la intuición y la composición de lo múltiple) y el entendimiento (para el concepto de la representación de la unidad de esta composición). Puesto que aquí el juicio no tiene como fundamento ningún concepto del objeto, solo puede consistir en la subsunción de la propia imaginación (frente a una representación por medio de la cual me es dado el objeto), bajo la condición de que el entendimiento pueda llegar así de la intuición a los conceptos. Esto quiere decir que, la libertad de tales juicios consiste justamente en el hecho de que la imaginación esquematiza sin concepto. El juicio de gusto debe fundarse así en el mero sentimiento de vivificación recíproca entre la imaginación, en su libertad, y el entendimiento, en su legalidad, esto es, fundarse en un sentimiento que permite juzgar al objeto según la adecuación de la representación (por medio de la cual es dado el objeto) para el fomento de las facultades del conocimiento en su libre juego." Ibídem p. 287.

49 De esta forma se rechazaba la tentativa sensualista de identificar el placer estético con el sentimiento de agrado. En este punto, el planteo de Kant parece coincidir con el de Moritz en la medida en que en ambos casos se trataba de diferenciar belleza y utilidad por medio del concepto de Zweckmäßigkeit. Desde la perspectiva de Peter Szondi, sin embargo, Kant continuaba pensando esta "disposición a fin" como un fenómeno de la sensibilidad y situándose, por ende, dentro de los límites de la estética de los efectos. A la superioridad de la perspectiva de Moritz en este aspecto se refiere Szondi en los siguientes términos: "La fórmula en la obra misma es indisociable de un programa completo con el cual se despide el pensamiento estético del siglo (la estética de los efectos)." Peter Szondi. Poetik und Geschichtsphilosophie I. Frankfurt: Suhrkamp, 1974, p. 98. Desde nuestro punto de vista, no obstante, Szondi pierde de vista en qué medida la fundamentación kantiana del juicio estético se alejaba de la estética de los efectos e introducía tópicos que serían desarrollados de una manera acabada en el marco de la filosofía idealista del arte.

50 En este punto tomamos distancia de la lectura de Zuckert en la medida en que esta autora remite el sentimiento de belleza a cualidades objetivas. Al respecto Zuckert sostiene: "es la forma de un objeto 
ba tanto la validez de la explicación mecánico-causal como el carácter incondicionado de la libertad, esto es, aquellos dos elementos que eran puestos en duda por las posturas que remitían la creación artística a la potencia vital de una naturaleza productiva. Pero gracias a la solución kantiana del problema se garantizaba también la posibilidad de un tránsito entre la subjetividad y las leyes del universo natural. Esto último resultaba particularmente importante a la hora de dar cuenta del carácter práctico de nuestras facultades subjetivas, es decir, de demostrar que estas últimas se hallaban capacitadas para su efectiva aplicación. Pues, así entendido, el placer estético venía a confirmar el carácter enlazable de dichas facultades y, con él, el hecho de que las mismas resultaban adecuadas para el conocimiento en general. En este sentido, la experiencia estética iluminaba una zona oscura de la filosofía crítica en la medida en que suspendía el uso determinante de las facultades cognitivas a los fines de ofrecerle al hombre la posibilidad de experimentarse a sí mismo como sujeto, es decir, como poseedor de determinadas fuerzas subjetivas que era capaz de emplear con éxito en el plano cognoscitivo real ${ }^{51}$.

\section{Consideraciones finales}

A lo largo de estas páginas hemos intentado reconstruir el contexto en el cual se produce el giro hacia una estética de carácter idealista. Según hemos podido constatar, la reflexión estética no asumió desde un primer momento funciones de carácter filosófico sino que procuró dar respuesta, en principio, a la crisis de legitimación artística que se seguía de la corrosión de los supuestos histórico-naturales clásicos. En este sentido, sería posible afirmar que el propio afán de los pensadores estéticos de finales del siglo XVIII por sostener sobre nuevas bases la objetividad de la representación artística jugó un rol fundamental a la hora de convertir a la obra de arte misma en un recurso adecuado para afrontar el problema moderno de la contingencia. Esto es, la temporalización de las formas orgánico-naturales limitó las pretensiones nomológicas al ámbito de los fenómenos inorgánicos y tornó impensable, de esta forma, toda posible fundamentación de la belleza artística que tomase como punto de referencia la racionalidad intrínseca del orden natural. Privadas de todo referente externo, las nuevas perspectivas estéticas debieron concentrarse en los aspectos no miméticos de la propia representación. Ya sea en la variante vitalista de Herder o en la deriva clasicista y formalista de Moritz, tales elementos fueron dotados así de un carácter incondicional que los habilitaba sin más para asumir la tarea filosófica de superar la historia en el marco de la propia temporalidad.

Pero si de esta forma se convertía al arte en el recuerdo de una naturaleza perdida, no por ello se resolvía de manera adecuada el problema de la legitimidad de la belleza artística. Pues, las perspectivas mencionadas se hallaban obligadas a escoger entre la remisión de esta última a una fuerza absolutamente indeterminada o su derivación a partir de una instancia de carácter intencional. Según analizamos a lo largo del presente artículo, la primera de estas opciones impedía dar cuenta de la necesidad de las configuraciones artísticas parti-

lo que lo hace bello". Cf. Rachel Zuckert. "The Purposiveness of Form: A Reading of Kant's Aesthetic Formalism". Journal of the History of Philosophy, 44.4, 2006, p. 600.

${ }^{51}$ Christoph Menke. Op. cit. p. 33. 
culares, 52 mientras que la segunda equiparaba la representación artística a la producción de artefactos de carácter instrumental. Por este motivo, a la hora de explicar el origen del fenómeno estético, Kant hacía referencia a un juicio de naturaleza subjetiva. Según pudimos advertir, el filósofo crítico no se limitaba a precisar así algunos conceptos generales de la tradición psicológico-efectual sino que introducía, más bien, una serie de elementos que devendrían fundamentales para el desarrollo de una estética de carácter idealista. Concretamente, Kant vinculaba de esta forma el placer estético a la forma de una subjetividad unificada. ${ }^{53}$ Pues, el estado en el cual se posicionaba el sujeto durante la experiencia estética se definía a partir del acuerdo espontáneo de sus facultades cognitivas. A esta concordancia remitía la idea kantiana de un "libre juego" de la sensibilidad y del entendimiento, esto es, a un tipo de correspondencia entre ambas disposiciones que, a diferencia de lo que sucedía en los juicios determinantes, no se desprendía de la presencia de un concepto de carácter general 54 .

Como ya mencionamos, la ausencia de toda determinación conceptual le permitía a Kant diferenciar al estado estético de aquella esfera en la cual tenían lugar los procesos de carácter cognoscitivo. En este sentido, sería posible sostener que la reflexión kantiana se orientaba a fundamentar la autonomía del juicio de gusto con respecto a los diversos usos determinantes de las facultades o disposiciones subjetivas. Sin embargo, por medio de esta diferenciación, el estado que posibilitaba la experiencia estética obtenía una función inédita en relación al plano específicamente cognoscitivo. Pues, en la medida en que dicho estado aludía a la libre concordancia entre el entendimiento y la imaginación, el juicio estético se presentaba como un mecanismo adecuado para experimentar la disposición a fin de las fuerzas subjetivas para un uso cognitivo en general. De esta manera se establece una tensión entre la fundamentación kantiana de la autonomía de la dimensión estética, por una parte, y su caracterización del placer estético en términos de un estado de libre concordancia entre las facultades subjetivas, por la otra. Pues, la interrupción de las funciones subjetivas habituales, que tenía lugar en la esfera estética, no introducía una ruptura real en el terreno de la praxis determinante, sino que apuntalaba, más bien, el uso extra-estético de las propias fuerzas subjetivas, allí donde esto ya no resultaba posible en términos estrictamente objetivos.

Sin embargo, no fue Kant, sino Schiller, el encargado de vincular la figura de una subjetividad reconciliada con el problema de la legitimación de la belleza artística. De esta manera, la elevación de la obra artística por encima de la contingencia histórica, que antiguamente había sido garantizada en función de una referencialidad de carácter ontológico,

\footnotetext{
52 En este sentido, la estética herderiana se hallaba atravesada por la misma dificultad que su teoría del conocimiento. Esto es justamente lo que le reprochaba Kant en su reseña de Ideas. Esto es, que el carácter absolutamente indeterminado de la fuerza genética originaria volvía imposible la explicación de las formas orgánicas naturales.

53 Ginsborg hace referencia a una "normatividad primitiva" al analizar la concepción kantiana del juicio de gusto. Sin embargo, lo que está en juego aquí para la autora es más la validez intersubjetiva del conocimiento empírico que la posibilidad de garantizar la unidad del sujeto. Hannah Ginsborg. "Thinking the Particular as Contained Under the Universal". Rebecca Kukla (Ed.) Aesthetics and Cognition in Kant's Critical Philosophy. Cambridge, Cambridge University Press, 2006, p. 35 y p. $58 \mathrm{n}$.

54 Immanuel Kant. Op. Cit. p. 219.
} 
pasaba a presentarse como un "préstamo" de la propia subjetividad. Pero Schiller no se limitaba a concebir la representación artística bajo la forma de la libertad subjetiva, sino que avanzaba hasta convertir al ámbito estético mismo en una condición necesaria para la existencia de la propia subjetividad55. Así, quedaba definitivamente consolidado el vínculo entre estética y subjetividad que, en términos indirectos, había afirmado Kant al remitir la belleza al libre juego de las facultades subjetivas. No obstante, tampoco eran pocas las dificultades que se hallaban contenidas en este modelo estético. Pues, si la objetividad de la obra de arte era salvada por medio de la referencia a una subjetividad reconciliada, esta última resultaba dependiente del proceso formativo que tenía lugar por intermedio de la propia experiencia estética. En este punto era posible advertir la confusión de terrenos que suponía la equiparación idealista del placer estético con el juego armónico de las facultades subjetivas. Pues, en la medida en que la naciente sociedad burguesa solo dejaba aparecer la libre concordancia de las facultades humanas bajo la forma de un imperativo, la sujeción de la esfera estética al principio del juego - esto es, al modelo de la "finalidad sin fin"- debía traer aparejado el sometimiento del arte a funciones y objetivos de carácter extra-estético. Este descubrimiento se encontraría a cargo del joven escritor Friedrich Schlegel quien, en algunas notas de mediados de los años 90, tacharía de dogmática a la interpretación de Schiller del escepticismo estético kantiano ${ }^{56}$. Pero el análisis del debate en torno a la herencia de la estética kantiana, que tendría lugar en Alemania desde finales del siglo XVIII, se encuentra más allá de los límites del presente trabajo.

\section{Referencias bibliográficas}

Allison, H.: "Kant's Antinomy of Teleological Judgment”. Southern Journal of Philosophy, vol. 30, 1991, pp. 25-42.

Baumgarten, A. G.: Aesthetica. Hildesheim: Georg Olms, 1970.

Beck, L.W.: Early German Philosophy. Cambridge: Belknap Press, 1969.

Bierbrodt, J.: Naturwissenschaft und Ästhetik, 1750-1810. Würzburg: Königshausen und Neumann, 2000.

Blumenbach, J.F.: Beiträge zur Naturgeschichte. Göttingen: Johann Christian Dieterich, 1790.

Bubner, R.: „Über einige Bedingungen gegenwärtiger Ästhetik“. Neue hefte für Philosophie. Göttingen, Vandenhoeck \& Ruprecht 1973, V. 5, 1773, pp. 38-73.

Buffon, G.-L. L.: Histoire Naturelle, Générale et Particulière, avec la description du Cabinet du Roy. Tome Sixième. Paris: de 1' Imprimerie Royale, 1756.

FÖRSTER, E.: „Die Bedeutung von $§ \S 76,77$ der 'Kritik der Urteilskraft' für die Entwicklung der nachkantischen Philosophie“. Zeitschrift für philosophische Forschung, vol. 56, 2002, pp. 169-190.

55 Para el primer momento se puede consultar Kallias. Para el segundo, en cambio, las Cartas sobre la educación estética del hombre. Cf. Friedrich Schiller. Kallias. Cartas sobre la educación estética del hombre. Trad. Feijóo, J. y Seca, J. Barcelona, Anthropos, 2005, p. 19, p. 241.

56 Friedrich Schlegel. „Von der Schönheit in der Dichtkunst“. Kritische Friedrich Schlegel-Ausgabe. Ed. E. Behler, H. Einchner, J.J. Anstett et al. München, Paderborn, Wien, Schöningh, 1981, p. 11. 
Foucault, M.: Las palabras y las cosas. Trad. Elsa Cecilia Frost. Barcelona: Planeta, 1984.

FrICK, W.: Providenz und Kontingenz. Untersuchungen zur Schicksalssemantik im deutschen und europäischen Roman des 17. und 18. Jahrhunderts I. Tübingen: Niemeyer, 1988.

FriGO, G. F.: „Die stete und feste Gang der Natur zur Organisation“. Breidbach, Olaf y Paul Ziche (Eds.) Naturwissenschaften um 1800. Weimar: Hermann Böhlaus Nachfolger, 2001, pp. 27-46.

GALFIONE, M.V.: "Historia Natural y temporalización: Algunas consideraciones sobre la historia natural de Buffon”. História, Ciências, Saúde - Manguinhos. Vol.20/n. 3, pp. 813829.

Ginsborg, H.: "Kant on Aesthetic and Biological Purposiveness". Reath, Andrews et al. (Eds.) Reclaiming the History of Ethics: Essays for John Rawls. Cambridge: Cambridge Press, 1997, pp. 329-360.

Ginsborg, H.: The role of taste in Kant's Theory of cognition. New York: Garland, 1990.

Ginsborg, H.: "Thinking the Particular as Contained Under the Universal". Aesthetics and Cognition in Kant's Critical Philosophy. Kukla, Rebecca (Ed.) Cambridge: Cambridge University Press, 2006, pp. 35-60.

Ginsborg, H.: "Two Kinds of Mechanical Inexplicability in Kant and Aristotle". Journal of the History of Philosophy, 42(1), 2004, pp. 33-65.

GotTsched, J.C.: Das Neueste aus der anmuthigen Gelehrsamkeit (Auszug aus der Herrn Batteux schönen Künsten aus dem einzigen Grundsatze der Nachahmung). Leipzig: Breithopf, 1754.

GotTsched, J.C.: Versuch einer Critischen Dichtkunst. Leipzig: Breitkopf, 1751.

GuYER, P.: Kant and the Claims of Taste. Cambridge: Harvard University Press, 1979.

GuYER, P.: "Organisms and the Unity of Science". Watkins, Eric (Ed.) Kant and the Sciences. Oxford: Oxford University Press, 2001, pp. 259-81.

HenRICH, D.: „Kunst und Natur in der idealistischen Ästhetik“. Jauß, H. Robert (Ed.) Nachahmung und Ilussion. München: Wilhelm Fink, 1969. 128-134.

Herder, J.G.: Ideen zur Philosophie der Geschichte der Menschheit. Ed. W. Pross. München/Wien: Carl Hanser, 2002.

Herder, J.G.: Shakespeare. Trad. Juan C. Probst Universidad Nacional de Buenos Aires. Facultad de Filosofía y Letras. Instituto de Literatura Anglogermánica, Buenos Aires, 1949.

Kant, I.: „Bestimmung des Begriffs einer Menschenrasse“. Kants gesammelte Schriften.

Tomo VIII. Hrsg. von der Königlich Preußischen Akademie der Wissenschaften, Berlin:

Walter de Gruyter, 1923, pp. 89-106.

Kant, I.: Crítica de la razón pura. Trad. Ribas, P. Madrid: Alfaguara, 1998.

Kant, I.: Kritik der Urteilskraft. Kants gesammelte Schriften. Tomo V. Hrsg. von der Königlich Preußischen Akademie der Wissenschaften, Berlin: Walter de Gruyter, 1913.

KANT, I.: „Recensionen von J.G. Herders Ideen zur Philosophie der Geschichte der Menschheit“. Kants gesammelte Schriften. Tomo VIII. Hrsg. von der Königlich Preußischen Akademie der Wissenschaften, Berlin: Walter de Gruyter, 1923, pp. 43-66. Traducción al español de Roldan Panadero, Concha y Rodríguez Aramayo, Roberto. Kant, Immanuel. "Recensiones sobre la obra de Herder Ideas para una filosofía de la 
historia de la humanidad". Ideas para una historia universal en clave cosmopolita y otros escritos sobre Filosofía de la Historia. Madrid: Tecnos, 1994.

KanT, I.: „Über den Gebrauch teleologischer Principien in der Philosophie“. Kants gesammelte Schriften. Tomo VIII. Hrsg. von der Königlich Preußischen Akademie der Wissenschaften, Berlin: Walter de Gruyter, 1923, pp. 157-184.

KANT, I.: „Von den verschiedenen Rassen der Menschen“. Kants gesammelte Schriften. Tomo II. Hrsg. von der Königlich Preußischen Akademie der Wissenschaften, Berlin: Walter de Gruyter, 1912, pp. 427-443.

KLICHE, D.: „Ästhetik“. Barck, Karlheinz et al. (Eds.) Ästhetische Grundbegriffe Historisches Wörterbuch in sieben. Tomo I. Stuttgart/Weimar: Metzler, 2010.

Kupke, N.: "Caves, fossils and the history of the earth". Cunningham, A. et al. (Eds.) Romanticism and the sciences. New York: Cambridge Univ. Press, 1990, pp. 241-259.

LeIBNIZ, G.W.: Der Briefwechsel mit G.W. Leibniz von 1715/1716. Hamburg: Felix Meiner, 1990.

LeIBNIZ, G.W.: Los principios de la naturaleza y de la gracia. Trad. García Morente. México: Porrúa, 1977.

LEPENIES, W.: Das Ende der Naturgeschichte. Frankfurt: Suhrkamp, 1978.

Longuenesse, B.: Kant and the Capacity to Judge. Trad. Charles T. Wolfe. Princeton/Oxford: Princeton University Press, 2000.

Marquard, O.: „Die Krise des Optimismus und die Geburt der Geschichtsphilosophie“. Lauer, G. et al. (Eds.) Das Erdbeben von Lissabon und der Katastrophendiskurs im 18. Jahrhundert. Göttingen: Wallstein, 2008, pp. 205-215.

Mclaughlin, P.: Kant's Critique of Teleology in Biological Explanation: Antinomy and Teleology. New York: Mellen, 1990.

Menke, C.: Estética y negatividad. Trad. Gustavo Leyva. Buenos Aires: FCE, 2011.

MENKE, C.: Kraft. Frankfurt: Suhrkamp, 2008.

Menke, C.: „Subjektivität“. Barck, Karlheinz et al. (Eds.) Ästhetische Grundbegriffe Historisches Wörterbuch in sieben. Tomo V. Stuttgart/Weimar: Metzler, 2010.

Metzger, S.: Die Konjektur des Organismus Wahrscheinlichkeitsdenken und Performanz im späten 18. Jahrhundert. München: Wilhelm Fink, 2002.

Moritz, K.P.: Schriften zur Ästhetik und Poetik. Kritische Aufgaben. Tübingen: Walter de Gruyter, 1962.

Palti, E.: Aporías. Tiempo, modernidad, sujeto, historia, nación. Buenos Aires: Alianza, 2001.

PoliansKi, I.: „Natursystem, Systemästhetik und das Überleben der Physikotheologie. Eine Jenaer Botanikgeschichte um 1800“. Wegner, Reinhard (Ed.) Kunst-Die andere Natur. Göttingen: Vandenhoeck y Ruprecht, 2004, pp. 125-134.

Ostermann, E.: Das Fragment. Geschichte einer ästhetischen Idee. München: Wilhelm Fink, 1991.

Riedel, F.J.: Philosophische Bibliothek. Tomo 1. Wien/Jena: Gebauer, 1769.

RiEDEL, M.: „Historizismus und Kritizismus. Kants Streit mit G. Forster und J.G. Herder“. Urteilskraft und Vernunft. Kants ursprüngliche Fragestellung. Frankfurt am Main: Suhrkamp, 1989, pp. 148-170. 
RitTER, J.: „Ästhetik, ästhetisch“. Ritter, Joachim. at al. (Eds.) Historisches Wörterbuch der Philosophie. Tomo I. Darmstadt: Wissenschaftliche Buchgesellschaft, 1971.

Schiller, F.: Kallias. Cartas sobre la educación estética del hombre. Trad. Feijóo, J. y Seca, J. Barcelona: Anthropos, 2005.

Schlegel, F.: „Von der Schönheit in der Dichtkunst“. Kritische Friedrich SchlegelAusgabe. E. Behler, H. Einchner, J.J. Anstett et al. (Eds.) München, Paderborn, Wien, Schöningh, 1981.

Soto Bruna, M.J.: "La aesthetica de baumgarten y sus antecedentes leibnicianos". Anuario Filosófico, vol. 20, 1987, pp. 181-190.

SzCZEPANSKI, J.: Subjektivität und Ästhetik. Gegendiskurse zur Metaphysik des Subjekts im ästhetischen Denken bei Schlegel, Nietzsche und de Man. Bielefeld: Transcript, 2007.

Szond, P.: Poetik und Geschichtsphilosophie I. Frankfurt: Suhrkamp, 1974.

WolfF, C.F.: Theorie von der Generation in zwei Abhandlungen erklärt und bewiesen. Hildesheim: Robert Herrlinger, 1966.

Zамміто, J.H.: „Herder, Kant, Spinoza und die Ursprünge des deutschen Idealismus“. Heinz, M. (Ed.) Herder und die Philosophie des deutschen Idealismus. Amsterdam y Atlanta: Rodopi, 1997, pp. 107-145.

Zамmiто, J.H.: The Genesis of Kant's Critique of Judgment. Chicago: University of Chicago Press, 1992.

Zuckert, R.: Kant on Beauty and Biology. Cambridge: Cambridge Univ. Press, 2007.

ZuCKeRT, R.: "The Purposiveness of Form: A Reading of Kant's Aesthetic Formalism". Journal of the History of Philosophy, 44.4, 2006, pp. 599-622.

María Verónica Galfione

Universidad Nacional de Córdoba (Argentina)

veronicagalfione@yahoo.com.ar 